\title{
POLÍTICAS DE ESTÁGIO E O CONTEXTO DO SERVIÇO SOCIAL
}

\author{
Tatiana Machiavelli Carmo Souzal \\ Cirlene Aparecida Hilário da Silva Oliveira ${ }^{2}$ \\ Cléria Maria Lobo Bittar Pucci Bueno ${ }^{3}$
}

\section{RESUMO}

O presente artigo busca explorar o contexto do estágio supervisionado em Serviço Social tendo como ponto de partida as políticas de estágio brasileiras. É certo que a importância do estágio aumenta frente às profundas transformações no mundo do trabalho e ao constante desenvolvimento científico e tecnológico, provocando o acirramento das discussões sobre o tema e instigando a academia a repensar seu processo formador, notadamente o Serviço Social. O estágio tem como finalidade a vinculação da educação formal ao mundo do trabalho e a prática social. No Serviço Social, o estágio supervisionado constitui-se como elemento do processo formativo, sendo que nesse locus, o estagiário tem a possibilidade de decifrar as relações institucionais e elaborar novos conhecimentos a partir do conhecimento das expressões da questão social que constituem o objeto de intervenção profissional. Nesse sentido, o estágio prático tem como função preponderante contribuir para que o estagiário aproprie-se do significado social do Serviço Social e da construção de sua identidade profissional, individual e coletiva. O desafio posto, na contemporaneidade, é o de direcionar o estagiário à formação reflexiva e analítica, a fim de que as práticas do Serviço Social não incidam apenas na imediaticidade.

PALAVRAS-ChAVE: Políticas de Estágio, Estágio Supervisionado, Serviço Social, Formação Profissional

\footnotetext{
${ }^{1}$ Psicóloga, Doutoranda no Programa de Pós-Graduação em Serviço Social da UNESP/Franca; especialista em Psicopedagogia; membro do Grupo de Estudo e Pesquisa em Formação Profissional em Serviço Social (GEFORMSS).

${ }^{2}$ Docente da Graduação e do Programa de Pós-Graduação em Serviço Social da UNESP/Franca; líder do Grupo de Estudos e Pesquisa Formação Profissional em Serviço Social; Supervisora da Unidade Auxiliar Centro Jurídico Social/UNESP.

${ }^{3}$ Docente da Graduação em Psicologia e do Programa de Pós-Graduação em Saúde. Revista Serviço Social \& Saúde. UNICAMP Campinas, v. IX, n. 9, Jul. 2010
} 


\section{INTRODUÇÃO}

A trajetória profissional do Serviço Social demonstra a centralidade do estágio supervisionado, ressaltando-o como locus gerador de aprendizagens teórico, técnicas e metodológicas. Para a compreensão da pertinência desse processo de ensinoaprendizagem, discorremos sobre as atuais políticas de estágio no Brasil e como o estágio em Serviço Social se insere neste cenário.

Buscamos conhecer também as atuais políticas de estágio no Brasil em decorrência da importância deste enquanto instrumento de aprendizagens profissionais. O estágio supervisionado é caracterizado como componente do projeto pedagógico do curso de Serviço Social. Como forma de vinculação entre educação formal, mundo do trabalho e prática social, o estágio supervisionado em Serviço Social tem centralidade no processo de formação profissional.

O estágio apresenta a função de contribuir para que o estagiário aproprie-se do significado social da profissão e da construção de sua identidade profissional, individual e coletiva, nesse sentido, caracteriza-se como contexto apropriado para a reflexão e a discussão.

\section{POLÍTICAS DE ESTÁGIO NO BRASIL}

A relação entre mundo do trabalho e educação no Brasil é discussão atual, especialmente quando refletimos sobre o espaço do estágio nesse cenário. Desde o Brasil Colônia até meados de 1940, essa vinculação é inexistente, tendo a educação caráter intelectual e humanista. Somente a partir desse período percebemos as primeiras relações entre educação e trabalho; também a partir dessa data inicia-se a discussão e a implementação do estágio enquanto prática profissional de aprendizagem. Tais dados 
rebatem na legislação que, apenas nos anos de 1970, promove progressivamente aproximação entre mercado de trabalho e educação.

As políticas brasileiras de estágio passam a normatizar esta etapa da formação profissional a partir do ano de 1977, com sucessivas leis e decretos (Lei 6.494/77, Decreto 87.497/82, Lei 8.859/94, Lei 9.394/96, Decreto 2.080/96, Lei 11.788/08). Desde esse período, o estágio é definido como sistema de treinamento prático do estudante, visando formação de habilidades técnicas e atitudes psicológicas requeridas pelo mundo do trabalho.

A importância do estágio aumenta frente às profundas transformações no mundo do trabalho e ao constante desenvolvimento científico e tecnológico, provocando o acirramento das discussões sobre o tema e instigando a universidade a repensar seu processo formador. Dentre as novas demandas para o exercício profissional, o estágio, enquanto atividade pedagógica, tem o papel de estimular o conhecimento da realidade social e desenvolver práticas que respondam às necessidades sociais.

Compreendemos o estágio como componente do projeto pedagógico de um curso e, dessa maneira, aspecto da formação acadêmico profissional que detém características singulares no processo de aprendizagem. Ao articular teoria e prática, de modo indissociável, o estágio promove o processo de ensinar e aprender, assim como também, a interação entre Universidade, organizações e sociedade.

Dentre as finalidades do estágio, encontramos a vinculação da educação formal ao mundo do trabalho e a prática social. A relação entre a dimensão acadêmica e a sociedade se perfaz por meio da prática do estágio, na qual o estagiário entra em contato com a realidade cotidiana. Nesse sentido, o estágio destaca-se como um dos componentes pedagógicos mais importantes na articulação privilegiada entre 
teoria-prática no processo de formação profissional, no conjunto de elementos constitutivos das diretrizes curriculares.

O estágio curricular é compreendido como ato educativo intencional, sistema de atividades de aprendizagem social, profissional e cultural e, enquanto procedimento didático-pedagógico, deve proporcionar ao estudante o desenvolvimento de habilidades requeridas ao exercício profissional.

No rol de diretrizes e apontamentos para a efetivação do estágio, encontramos as seguintes metas:

- Criar um campo de experiências e conhecimentos que constitua a possibilidade de articulação teórico-prática e que estimule a inquietação intelectual dos alunos;

- Desenvolver habilidades, hábitos e atitudes pertinentes e necessárias para aquisição das competências profissionais;

- Incentivar o interesse pela pesquisa e pelo ensino;

- Criar um espaço de transição entre a vida estudantil e a vida profissional, atenuando o impacto dessa transformação, base de emancipação e autonomia;

- Favorecer, por meio da diversificação dos espaços educacionais, a ampliação do universo cultural dos estagiários (PROAC, [2008]).

Considerando a Lei 6.494/77, é entendido como estagiário o estudante regularmente matriculado em cursos vinculados ao Ensino Superior público ou particular, que esteja comprovadamente freqüentando-os. Para que o estágio se firme é necessário que haja instrumento entre a Instituição de Ensino Superior (IES) e a pessoa jurídica de direito público ou privado interessado no estágio, denominado "Termo de Compromisso de Estágio”.

Conforme Decreto 87.497/82, em seu Artigo $2^{\circ}$, a aprendizagem decorrente do estágio deve ser efetivada a partir da inserção e "participação em situações reais de vida 
e trabalho de seu meio, sendo realizada na comunidade em geral ou junto a pessoas jurídicas de direito público ou privado, sob responsabilidade e coordenação da unidade de ensino". Dessa forma, observamos que a legislação preconiza a necessidade do estagiário estar em íntimo contato com a realidade, já que a aprendizagem profissional dá-se por meio dela.

A Lei 8.859/94 reconhece que o estágio pode se dar somente em unidades que tenham condições de proporcionar experiência prática na linha de formação do estagiário. Dessa forma, conforme a mesma lei, o estágio necessita ser planejado, executado, acompanhado e avaliado conforme o norteamento curricular.

Podemos verificar, também, que ampla parcela de responsabilidade no contexto de estágio recai sobre a unidade de ensino. Fica ao cargo dessa a inserção do estágio curricular na programação didático-pedagógica; a carga horária, duração e jornada do estágio; as condições imprescindíveis para caracterização e definição dos campos de estágio; e o sistema de organização, orientação, supervisão e avaliação do estágio. Nesse sentido, faz-se importante que a instituição promotora de estágio tenha condições de propiciar desenvolvimento sócio-cultural e científico na área de formação do estagiário, a partir de situações concretas e reais postas na realidade.

Segundo Decreto 2.080/96, compete à instituição de ensino ou à instituição concedente de estágio providenciar o seguro de acidentes pessoais ao estudante, resguardando-o de possíveis problemas de ordem trabalhista e zelando pela manutenção de sua vida, ainda que apenas no decorrer da realização do estágio.

Dentre os aspectos centrais na discussão sobre o estágio, encontramos a indissociabilidade entre teoria e prática. $\mathrm{O}$ engendramento entre o conhecimento e o fazer é diferencial no mundo contemporâneo; o estagiário necessita desenvolver essa 
competência de maneira que sua prática promova o processo de transformação social. Essa práxis é elemento diferenciador no decorrer da formação profissional.

A garantia da articulação entre prática e teoria, bem como a construção de perfil profissional condizente com as atuais demandas, só se efetiva pela supervisão. A supervisão de estágio deve conduzir à reflexão, estudo e compreensão das ações realizadas pelo estagiário, possibilitando a crítica e o crescimento pessoal e profissional. As experiências já vivenciadas no campo de estágio são ressignificadas pelo processo de supervisão. A possibilidade da supervisão, enquanto acompanhamento didático e sistemático, rechaça as práticas voltadas à imediaticidade e promove a criação do novo, garantindo a qualidade do estágio no caráter de ação pedagógica.

Destacamos que estágio não é emprego e não deve ser confundido com as políticas de primeiro emprego. Como tal, não deve ser pensando ou efetivado como solução de problemas sociais, tampouco como forma de precarizar as relações de trabalho. Por caracterizar-se como modalidade do processo de formação, a realização do estágio não implica em vínculo empregatício. Não é, portanto, a legislação trabalhista que referenda o estágio, mas sim as políticas de educação, em especial, as de estágio. Ora, se o estágio é regulamentado e compreendido como instrumento de promoção de aprendizagem pessoal e profissional, a implantação de estagiários no lugar de trabalhadores constitui-se em situação inaceitável, principalmente se pretendemos promover o desenvolvimento e emancipação humana.

$\mathrm{O}$ estágio profissional tem sido instrumento generalizado de fraude aos direitos sociais. Não raro encobre contratos de trabalho, não só pelo concurso doloso dos sujeitos-cedentes que nada mais querem do que contar com a força do trabalho sem os ônus sociais, como pela negligência das instituições de ensino que se limitam a cumprir os requisitos formais, sem se preocuparem com o acompanhamento pedagógico, equiparandoRevista Serviço Social \& Saúde. UNICAMP Campinas, v. IX, n. 9, Jul. 2010 
os a meras intermediadoras de mão-de-obra (CAMINHO apud COMISSÃO NACIONAL DE ESTÁGIO DO FORGRAD, 2004, online).

O descumprimento pela instituição de ensino das formalidades necessárias à regulamentação da prática do estágio incide na caracterização desse ato em mera intermediação de mão de obra, possibilitando que o estágio seja instrumento de fraude aos direitos sociais do trabalhador. A ocorrência cotidiana desse cenário levou o Ministério do Trabalho a executar a Notificação Recomendatória 741/2002, pela qual ressalta os objetivos do estágio e sua legislação.

Em decorrência da precariedade de legislações que norteiam o estágio curricular, o documento da Comissão Nacional de Estágios do ForGRAD (2004, online, grifo nosso) aponta alguns direcionamentos às Instituições de Ensino Superior (IES):

a) que a carga horária máxima dos contratos de estágio nãoobrigatório, realizado concomitantemente com o período de aulas, seja fixada em 30 (trinta) horas semanais e não superior a (6) seis horas diárias, por aluno. Tal jornada deve ser compatível com o horário escolar e preservar direitos fundamentais como saúde, segurança, educação, convivência familiar, cultura e lazer, sendo que excepcionalmente poderá ser admitido o máximo de 40 horas semanais, desde que o estágio seja realizado fora do período letivo.

b) desenvolver e implementar políticas e ações acadêmicas, administrativas e pedagógicas de incentivo à realização e à gestão de estágios.

O pouco aprofundamento das legislações vigentes, bem como a escassez de publicações, permite a fragilidade das ações das IES e das instituições promotoras de estágio. 
Dentre as mudanças ocorridas no panorama legislativo, vislumbramos a Lei 11.788 (BRASIL, 2008) que regula a situação dos estagiários no Brasil. Essa nova legislação, busca a garantia do estágio como parte do processo educativo e do projeto pedagógico do curso, bem como almeja reconhecer o estágio como um vínculo educativo-profissionalizante, supervisionado e desenvolvido como parte do projeto pedagógico. Ademais, esclarece a função do estagiário, da unidade de ensino e da parte concedente de estágio e busca dar ampla cobertura de direitos capazes de assegurar a cidadania no ambiente de trabalho. Sabemos, contudo, que a promulgação de nova lei não é garantia da aplicabilidade da mesma. Nesse sentido, as transformações ocorridas nas legislações, embora tragam benefícios aos estagiários, não garantem a efetivação dos direitos adquiridos, especialmente acerca das condições de saúde, segurança, educação, convivência familiar, cultura e lazer, que incidem diretamente na constituição subjetiva do estagiário e no processo educativo.

A desvalorização do estágio como estratégia pedagógica, no âmago da IES, pode acarretar em falhas ou lacunas no processo de desenvolvimento no qual o estudante se encontra, contribuindo para o sucateamento do Ensino Superior e para a ausência de qualidade na formação profissional.

Diante das novas demandas de produção e gestão do conhecimento, buscamos a efetivação do estágio como instrumento de capacitação técnica, de comprometimento ético-político e de desenvolvimento pessoal enquanto aspectos essenciais à preparação para o trabalho e o exercício da cidadania.

\section{ESTÁGIO SUPERVISIONADO EM SERVIÇO SOCIAL}

O estágio supervisionado encontra-se como elemento do processo formativo desde a fundação das primeiras escolas de Serviço Social no Brasil, em meados de 
1930. Desde a origem do curso, o estágio tem papel central na formação profissional, sendo percebido como fundamental para a garantia de qualidade nesse processo (ANDRADE, 2007).

Enquanto campo de treinamento da prática profissional do Serviço Social, o estagiário vivencia as relações sócio-históricas, dialéticas e contraditórias existentes nesse espaço, compreendendo a dinâmica peculiar do trabalho. Assim, ao entrar em contato com essa realidade, o estagiário tem a possibilidade de decifrar as relações institucionais e elaborar novos conhecimentos a partir do conhecimento das expressões da questão social que constituem o objeto de intervenção profissional.

O estágio representa, para o estudante, momento de contato com a realidade profissional. É a partir deste contexto de ensino-aprendizagem que se pode apreender a matéria prima do fazer profissional: a questão social. As atividades realizadas no campo de estágio possibilitam reflexão, crítica, descobertas, dúvidas presentes na dinâmica da realidade, tecendo o aprender. Neste sentido, o estágio supervisionado ganha centralidade no processo de formação profissional, já que se caracteriza como contexto apropriado para pensarmos as questões objetivas e subjetivas presentes em tal processo e por ser etapa do processo de treinamento prático da vida profissional.

O contexto de estágio proporciona o conhecimento da realidade social, oportunizando o contato com as múltiplas manifestações da questão social e o desenvolvimento da visão crítica para futuras intervenções. Dessa maneira, o estágio prático tem como função preponderante contribuir para que o estagiário aproprie-se do significado social do Serviço Social e da construção de sua identidade profissional, individual e coletiva. Fazemos nossas as palavras de Buriolla (1995) ao compreender o estágio como “[...] locus onde a identidade profissional do aluno é gerada, construída e 
referida; volta-se para o desenvolvimento de uma ação vivenciada, reflexiva e crítica e, por isso, deve ser planejado gradativa e sistematicamente" (p. 13).

Experienciar a natureza interventiva do Serviço Social, no cotidiano do estágio, possibilita ao estagiário apreender os papéis e atitudes dos profissionais, assim, na medida em que o estudante apropria-se da profissão, ele se percebe como membro da categoria profissional. Nesse processo de apropriação de conhecimentos teórico-metodológicos e ético-políticos, assim como de posturas profissionais, o estagiário tem a oportunidade de aproximar-se das práticas cotidianas que norteiam o exercício profissional do assistente social.

O fortalecimento da identidade profissional efetiva-se, também, a partir da elaboração crítica e reflexiva do exercício profissional, aliado ao conhecimento teórico-metodológico, técnico-operativo e ético-político.

Pelo estágio supervisionado, o estudante, além de se confrontar com a prática do Serviço Social, apreende o contexto mais amplo das relações da profissão com a sociedade, incorporando aspectos culturais e sócio-profissionais presentes neste contexto. De acordo com Pinto (1997), a simples presença do estudante no campo de estágio não garante o conhecimento da realidade da prática profissional. O estudante encontra significado no estágio nas dialéticas e contraditórias relações que são firmadas nesse contexto, impulsionando a aprendizagem.

Acreditamos que o papel intrínseco do estágio encontra-se na possibilidade de desenvolver o pensamento crítico dos estagiários à medida que ocorre a integração entre o estudo, a prática social e a reflexão analítica do fazer, dimensões estas que, quando integradas, possibilitam descobertas e a apropriação de elementos presentes no tecido social. 
O significado do estágio materializa-se a partir de aproximações sucessivas que o estagiário faz à realidade social mediatizadas pela fundamentação teórico-metodológica, e deve ser compreendido segundo as diretrizes curriculares do Serviço Social. Como atividade do processo ensino-aprendizagem, o estágio ocupa posição estratégica na formação profissional e articula profissão, conhecimento e realidade no processo de compreensão dos fenômenos sociais. Dada sua importância no processo de formação profissional, a carga horária mínima do estágio supervisionado em Serviço Social deve corresponder a $15 \%$ da carga horária do curso.

Nesse sentido, Oliva (1989) compreende o estágio curricular não como mera aplicação de conhecimentos adquiridos, nem como simplista adequação de estagiários ao mercado de trabalho, mas sim, como momento de estudo, pensamento e reflexão da prática social. A autora rompe com o pressuposto de que o estágio deva ser apenas conjunto de práticas pré-estabelecidas pela instituição. Ao superar tal entendimento, nos apresenta uma visão que prioriza a aprendizagem, ou seja, a articulação entre o pensar e o fazer.

O desafio posto, no panorama atual, é o de direcionar o estagiário à formação reflexiva e analítica, a fim de que as práticas do Serviço Social não incidam apenas na imediaticidade. Há, assim, que se ter o cuidado de não fazer do campo de estágio espaço voltado somente à informação teórica e/ou de exploração de mão de obra barata. Contrários a essa idéia, acreditamos que no contexto do estágio, o estagiário deve entrar em contato com experiências reais e cotidianas a fim de deparar-se, buscar compreender e almejar propor formas de enfrentamento da questão social em suas múltiplas determinações. O estágio supervisionado necessita corresponder com os pressupostos da formação profissional alicerçada e comprometida com os valores democráticos e com o projeto ético-político da categoria profissional. 
O campo de estágio é o espaço onde se torna possível a realização do estágio, é locus privilegiado de aprendizagem social, profissional e cultural, favorecendo inserção do estudante aprendiz, que vivencia situações reais de vida e trabalho. Por meio da demanda existente no campo de estágio, o estagiário entra em contato com questões referentes à profissão e específicas do cotidiano dos usuários atendidos. É certo que o campo de estágio não é isento de neutralidade e intenção, uma vez que contém toda gama de concepções, valores, compreensões de diversos indivíduos: estagiários, supervisores, usuários e demais profissionais. Nesse espaço, relações históricas, dialéticas e contraditórias são firmadas.

No processo de operacionalização do estágio supervisionado, destacamos a participação de três sujeitos: o estagiário, o assistente social supervisor de campo e o docente supervisor acadêmico. $\mathrm{O}$ direcionamento do estágio acontece na interação entre este três atores, de modo que esta triangulação promove o desenvolvimento do processo de aprendizagem. O vínculo, alicerçado na cooperação e na ética permite que o estagiário desenvolva habilidades profissionais e pessoais. Em contrapartida, se desconsiderarmos um desses sujeitos na efetivação do estágio, certamente estaremos prejudicando a constituição e desenvolvimento do estagiário.

Estágio e supervisão são aspectos da formação profissional que estão intimamente relacionados, e por isso, não podem ser estudados separadamente. Estágio e supervisão constituem-se em elementos indissociáveis e espaços privilegiados de vivência e exercício que garantem a apropriação de elementos imprescindíveis para a atuação profissional.

Não se pode dissociar estágio de supervisão, pois o primeiro é o contexto em que o aluno estabelece relações mediatas entre os conhecimentos teóricos e o trabalho profissional, desenvolve a capacitação técnico-operativa e reconhece a articulação entre a 
prática do Serviço Social e o contexto político, econômico e cultural das relações sociais. A supervisão é caracterizada pelo acompanhamento e pela orientação profissional ao aluno. Estágio e supervisão são espaços interdependentes, no processo ensino-aprendizagem (SIQUEIRA, 2006, p. 32).

Ora, se o estágio configura-se como momento de efetiva inserção do estudante no espaço sócio-institucional para a aprendizagem do exercício profissional, a supervisão é o locus de reflexão teórico-metodológica que orienta o estagiário em suas ações no campo do trabalho. A indissociabilidade entre estágio e supervisão é um dos principais fundamentos da formação profissional em Serviço Social. Esse fundamento possibilita grandes contribuições para estagiário e supervisor, pois permite que ambos tenham aprendizagem profissional, então a aprendizagem não é unilateral.

Assim como o estágio, a supervisão consiste em atividade organizada sob critérios normatizados, de acordo com a legislação específica do ensino superior. Deve ser realizada pelo profissional assistente social.

Como nos aponta Pinto (1986), a supervisão é momento que

[...] compreende o processo ensino-aprendizagem que se estabelece na relação do professor-supervisor com o aluno, a partir da atividade cotidiana do estágio, mediante uma dada programação que vise ao reconhecimento dos nexos entre os conhecimentos do Serviço Social e a realidade da prática profissional na sua relação com a demanda, com a instituição e com a realidade social (1986, p. 97).

É certo que a supervisão deva considerar as relações sociais existentes nesta esfera, promovendo o desenvolvimento e o crescimento do estagiário no enfrentamento das questões cotidianas presentes no campo de trabalho. A efetivação de tais aspectos pressupõe rigor do profissional ao planejar o momento de supervisão e executá-lo de maneira ética e respeitosa, exercendo sua autoridade democrática. 
A supervisão de estágio em Serviço Social compreende duas dimensões: supervisão de campo e supervisão acadêmica. Esses diferentes, mas complementares processos, têm por objetivo significar o processo de aprendizagem, bem como de construção da identidade profissional do estagiário.

[...] a supervisão em Serviço Social é vista como um processo educativo, de ensino-aprendizagem, que se realiza na área do agir e ocorre em função da prática profissional, desenvolvendo o acompanhamento do trabalho prático cotidiano do aluno estagiário. A supervisão de estágio é essencial à formação do aluno de Serviço Social, enquanto lhe proporcione um momento específico de aprendizagem, de reflexão sobre a ação profissional. Supervisor e Supervisionado são sujeitos ativos do processo ensino-aprendizagem e da produção de um saber profissional, exigindo de ambos a convivência, ações pró-ativas e coresponsabilidade, como sujeitos co-participantes do processo educativo (MUNIZ, 1997, p. 30).

Partindo desse entendimento, podemos destacar a importância do papel do supervisor no contexto do estágio. Sabe-se que o supervisor - por meio de sua competência, da sua função de educador, de seus valores e autoridade, etc. - é figura de destaque nesse cenário. Dessa maneira, faz-se necessário compreender o papel do assistente social supervisor acadêmico e de campo.

A supervisão acadêmica como espaço de discussão do processo de trabalho no qual o estagiário está inserido, permite a construção teórico-crítica do exercício profissional. Nesse sentido, o supervisor acadêmico tem como atributo o encaminhamento metodológico do estágio supervisionado.

Para isso, a supervisão, como prática docente intencional e politicamente definida no contexto de um projeto de formação, é o espaço propício para a reflexão que possibilita ao aluno a Revista Serviço Social \& Saúde. UNICAMP Campinas, v. IX, n. 9, Jul. 2010 
articulação entre o pensar e o agir profissional, não se reduzindo à tarefa de treinamento de habilidades, nem tampouco só à tarefa de articulação da teoria à prática.

A supervisão, como trabalho docente, é o espaço para que o encontro do aluno com a prática profissional ultrapasse os limites do imediatismo e da superficialidade do real para, refletidos tornarem-se constructos do processo de aprendizagem profissional (PINTO, 1997, p. 120).

Ao professor supervisor está facultada a ação de oferecer e orientar o estagiário quanto ao referencial, bem como o desenvolvimento de estudos e pesquisas na área de estágio. São atividades destinadas a esse ator, a organização e desenvolvimento de oficinas temáticas, com o intuito de facilitar a discussão e o debate acerca da temática. Dessa forma, compete ao supervisor acadêmico auxiliar o estudante, mediante dada programação, a construir o nexo existente entre os conhecimentos do Serviço Social e a realidade concreta da prática profissional e suas conseqüentes relações sociais.

Na supervisão acadêmica o estagiário encontra possibilidades de significar as questões vivenciadas no campo de estágio à luz da fundamentação teóricometodológica. Nesse sentido, Andrade (2007) percebe e apreende a supervisão acadêmica com o papel de "[...] acompanhar o aluno em relação ao seu desempenho, identificar carências e buscar superá-las, estimular atitude investigativa, contribuir na identificação de elementos particulares e universais, orientar bibliografia, entre outros" (p. 106).

Enquanto agente do processo de aprendizagem profissional, espera-se que o supervisor de campo seja o "elo privilegiado" entre a prática profissional e o processo de ensino acadêmico (OLIVEIRA, 2004). Nesse sentido, cabe a esse profissional 
acompanhar as atividades desenvolvidas pelo estagiário na instituição, possibilitandolhe a compreensão da dinâmica do cotidiano profissional, a orientação quanto à elaboração de documentos, a supervisão no planejamento e execução de intervenções, e, ainda, a avaliação qualitativa do estudante. Em síntese, espera-se que o supervisor, por meio do constante diálogo, possa contribuir no crescimento e amadurecimento profissional do estagiário.

Compartilhamos o pensamento de Buriolla (1996) ao salientar que a supervisão requer profissional que tenha amplo domínio das particularidades e habilidades inerentes à ação supervisora. A competência profissional e o cunho ético são características primordiais ao supervisor. O supervisor tem o papel de conduzir o processo de supervisão e ao mesmo tempo em que é mediador de conhecimentos, tem a tarefa de facilitar a aprendizagem. A habilidade do supervisor em orientar o estagiário torna-se ampliada na relação de confiança, empatia e aceitação entre ambos. Isso implica em considerar que supervisor e estagiário possuem valores, visão de homem/mundo, dificuldades diferentes, e que o respeito mútuo deve ser o valor maior presente na relação.

Dentre as dificuldades postas, no presente, temos a formação continuada dos supervisores de campo, preocupação que se encontra nas agendas da ABEPSS. As ações do supervisor de campo, em diversas situações, são exercidas sem sistematização e reflexão, comprometendo o vínculo entre teoria e prática. Essas dificuldades provocam lacuna, afetando os objetivos do estágio supervisionado e, por conseguinte, de todo processo de formação profissional.

O estágio no curso se pretende articulado teórica e praticamente com o projeto social das classes subalternas em suas relações com as forças dominantes [...]. Nesse sentido, o estágio deixaria de ser pensado como momento de verificação da teoria 
adequada à prática - viés formalista - para ser um desvendar das aparências no fazer e no cuidar da ciência, ao elaborar leis e princípios, as recorrências e regularidades que presidem os processos e fenômenos estudados, enquanto momentos do trabalho de produção, negação e superação do real (OLIVA, 1989, p. 152).

É certo então afirmarmos que o estágio tem totalidade maior, no qual a prática descolada da realidade concreta não promove nenhuma mudança neste panorama. Queremos afirmar que, ao restringir-se a mera execução de procedimentos burocráticos, o estágio perde a dimensão interventiva. É nesse sentido que o estágio revela-se como possibilidade criativa de transformação de si mesmo e da realidade, já que o estagiário necessita (re)pensar e (re)elaborar suas concepções e ações. Sabemos que este processo de aprendizagem se efetiva por meio da supervisão ${ }^{4}$.

Ressaltamos aqui o momento da supervisão como componente do processo de aprendizagem do estagiário e, por isso mesmo, um aspecto alicerçado conscientemente ou não - na concepção de educação do supervisor, que tem a qualidade de educador junto ao estagiário.

A supervisão permite a reflexão a partir da suspensão da realidade vivenciada, em que as dúvidas e questionamentos podem ser respondidos, abstrações são feitas, os conflitos elaborados e significados e as práticas repensadas sob viés crítico e pautado no referencial teórico utilizado. Como nos aponta Pacchioni (2000), no fazer cotidiano da supervisão se descobre o significado de pensar a ação, podendo despertar no estagiário a importância desse acompanhamento ao longo da vida profissional. A ação supervisora implica em conduzir o estagiário a desvelar a realidade social existente

\footnotetext{
${ }^{4}$ Não se apresenta como nosso objetivo analisar a produção referente à supervisão de estágio; apenas nos atentamos a este aspecto como elemento do processo de estágio. Sugerimos consultar a obra "Supervisão em Serviço Social: o supervisor, sua relação e seus papéis" (BURIOLLA, 1996).

Revista Serviço Social \& Saúde. UNICAMP Campinas, v. IX, n. 9, Jul. 2010
} 
no campo de trabalho pelas múltiplas expressões da questão social e, a partir disso, possibilitar a construção de estratégias eficazes de enfrentamento.

O supervisor tem a responsabilidade de garantir estágio que contribua na formação profissional do estagiário, de modo a assegurar-lhe experiência prática qualitativa, em que suas ações possam ser matéria-prima para reflexão crítica e ética.

A supervisão constitui-se num encontro pedagógico, no qual o trabalho educativo desenvolvido pelo ato concreto da supervisão deva valorizar a autoconsciência do estagiário. Nesse sentido, o supervisor deve conhecer os interesses, motivações e necessidades do estagiário, enfim, conhecer suas condições pessoais, sua realidade de vida, como nos lembra Pacchioni (2000). Para que o processo ensinoaprendizagem efetive-se, o estagiário necessita ser compreendido como ser ativo e participante, que detém conhecimento prévio e potencialidades para o constante aprender. Esse olhar implica a superação da visão reducionista sobre o estagiário como mão-de-obra barata ou apenas como cumprimento de tarefas.

A atividade de ensino-aprendizagem, característica do processo de supervisão, possibilita que as ações realizadas pelo estagiário, bem como as situações vivenciadas possam ser (re)pensadas e (re)significadas a partir da perspectiva da dupla supervisor/estagiário. A reflexão permite a possibilidade de atribuir novos significados às atividades desenvolvidas durante o período de estágio.

[...] na medida em que o agir profissional é realizado, refletido e recriado em um processo de trocas mútuas e inter-relacionadas socialmente, na medida em que não existe aquele que ensina e aquele que aprende - pois ambos, supervisor e supervisionado, passam pelo processo (o supervisor ensina, mas ele também aprende do estagiário; o aluno-estagiário aprende, mas ele também ensina para o supervisor, dadas as individualidades e as experiências vivenciais diversas de cada um, coletivizadas) -, na medida em que a concepção da realidade e a 
visão de mundo têm influência no processo de ensino-aprendizagem, abrangendo as relações internas e externas (determinantes do contexto e do processo da Supervisão), estas influências, determinantes e determinadas, só podem gerar um produto no sujeito coletivo supervisor e supervisionado [...] (BURIOLLA, 1996, p. 58, destaque do autor).

É certo que o momento singular da supervisão, quando efetivado como prática educativa, permite que o estagiário possa reconhecer-se enquanto ser criativo, detentor de saberes. Ainda, traz consigo a possibilidade do supervisor refletir sobre sua prática profissional, já que os questionamentos levantados pelo estagiário oxigenam a prática do profissional. Por meio da interatividade presente no contexto de supervisão, nasce o momento de aprendizagem profissional e pessoal para ambos, supervisor e estagiário; isto é, o conhecimento coletivamente construído.

Espera-se que o supervisor - em qualquer das duas dimensões - tenha rigor teórico aliado à experiência prática ao nível teórico-metodológico, constantemente refletida. A partir dessas características possa desenvolver postura crítica e contribuir na construção de novos conhecimentos, bem como a escolha de estratégias didáticas que favoreçam a democracia no processo de supervisão. Dessa forma, supõe-se que o supervisor desenvolva habilidades técnicas, habilidades conceituais e habilidades sociais (BURIOLLA, 1996).

Ora, para que os objetivos do processo de supervisão sejam efetivados e contribuam na formação profissional, é necessário que ela seja sistemática, constante, planejada e avaliada. Ademais, que seja momento de reflexão do exercício profissional à luz da teoria. A efetivação desses propósitos requer ação integrada e consonante entre supervisor de campo e supervisor acadêmico.

Compreendendo que o supervisor acadêmico contribui no encaminhamento metodológico e o supervisor de campo, na dinâmica do cotidiano do campo de estágio, 
acreditamos que as ações destes profissionais estão interligadas, de maneira que cada um colabora com alguns aspectos, buscando, sempre, o desenvolvimento profissional do estudante.

Ainda, estágio e supervisão são elementos indissociáveis do mesmo processo. Romper com a indissociabilidade entre estágio e supervisão, leva à desconsideração dessa característica essencial e à compreensão como atividades estanques.

Por fim, as finalidades do estágio são mais facilmente alcançadas quando o planejamento do estágio foi realizado de maneira consciente e crítica, pois permite que os papéis e atribuições de cada elemento desse processo fiquem claras: desde as diretrizes da ação do estagiário como até as funções dos supervisores. Dessa forma, o plano de estágio torna-se "bússola" que norteia e orienta todo o processo.

Para que o objetivo da aprendizagem profissional seja concretizado, no decorrer do estágio supervisionado é importante que a supervisão colabore no desenvolvimento das diversas competências (teórico-metodológicas, sociais, cognitivas) do estagiário necessárias ao futuro desempenho profissional almejado pela categoria profissional e pela sociedade brasileira.

Percebemos, desse modo, que os diferentes sujeitos - estagiário, supervisor de campo, supervisor acadêmico e as demais pessoas presentes no cotidiano do campo de estágio - envolvidos no contexto do estágio apresentam papéis diferenciados, papéis estes que pressupõem funções, responsabilidades, posturas, atitudes e valores também diferentes. É nesse ponto que encontramos uma das lacunas presentes no estágio supervisionado em Serviço Social. O espaço do estágio é, por garantia o espaço da relação, do convívio das trocas e, por isso, espaço privilegiado para a compreensão das emoções. 
Nesse sentido, pensar o contexto do estágio supervisionado em Serviço Social é desafio que se impõe à categoria profissional, às unidades de ensino e aos estudantes/estagiários. É certo que essa reflexão deve ser permeada pelas experiências reais e concretas vivenciadas nos campos de estágio, aliada à responsabilidade particular de cada indivíduo envolvido neste processo. Sabemos que o caminho é tortuoso, mas muitos entraves já foram superados, muitas possibilidades estão sendo alcançadas. Há, contudo, limites a ultrapassar.

Enquanto processo qualitativo, o estágio carrega consigo aspectos cognitivos, permeado pelas habilidades teórico-medodológicas e técnico-operativas. Juntamente a isso, a dimensão emotiva encontra-se pulsante. Usamos as palavras de Bordenave ao ressaltarmos que no processo de aprendizagem vivenciado no estágio também estão presentes:

[...] sentimentos de curiosidade, tensão, ansiedade, angústia, entusiasmo, frustração, alegria, emoção estática, impaciência, obstinação, e várias outras emoções acompanham o processo de perceber, analisar, comparar, entender, etc., que configuram o processo de aprender (BORDENAVE apud PINTO, 1997, p. 58).

O fenômeno educativo que ocorre entre estagiário e supervisor é uma ação para o intercâmbio de significados e sentimentos, de maneira em que há construção de conhecimentos por meio de pensamentos, ações e sentimentos.

Acreditamos que esses aspectos representam lacuna na compreensão do estágio e seu papel na formação profissional. Esse é tema que não encontra espaço na discussão contemporânea realizada acerca do estágio supervisionado, nem nas atuações cotidianas, muito menos nas agendas de pesquisa. Nossa prática sustenta a percepção que a garantia de um contexto que considere os aspectos afetivo-emocionais, expressos pela 
intersubjetividade, revela-se também como garantia de um diferencial, um salto qualitativo no processo de formação profissional.

\section{CONSIDERAÇÕES FINAIS}

O estágio supervisionado configura-se como elemento central no processo de aprendizagem profissional do Serviço Social. Dada sua centralidade nesse processo, necessita ser assimilado à luz das políticas de estágios brasileiras.

Em decorrência das profundas mudanças no mundo do trabalho, a temática estágio deve ser intensamente discutida e repensada, especialmente frente à precarização do trabalho e a utilização do estágio em diversificadas finalidades.

Nesse sentido, compreender as políticas de estágio no âmbito de sua trajetória histórica, revela-nos a evolução das legislações. As leis atuais mostram-se cuidadosas acerca da real papel do estágio e atributos do estagiário, apontando em direção do estágio em que aprendizagens são firmadas.

No âmago das políticas de estágio, compreendemos o cenário do estágio supervisionado em Serviço Social e seus principais atores - estagiário, assistente social supervisor de campo e assistente social supervisor acadêmico. Temos, assim, o estágio supervisionado como atividade pedagógica voltada à aprendizagem do exercício profissional e construção da identidade profissional do assistente social.

O estágio supervisionado, ao colocar o estagiário em contato com o ambiente real do trabalho do Serviço Social, cria oportunidades de confrontos e sínteses, estimulando e favorecendo a elaboração crítica e reflexiva do exercício profissional. Dessa forma, deve ser compreendido no âmbito do projeto de formação profissional almejado pela categoria profissional. 
Em nossa compreensão, a análise do estágio supervisionado deve acontecer em consonância com o projeto de formação profissional, do qual ele é parte integrante. O estágio é alternativa competente para o conhecimento da realidade concreta da sociedade, bem como espaço para a criação de alternativas para o enfrentamento das dificuldades presentes na sociedade.

\begin{abstract}
This article aims to explore the context of supervised traineeship in Social Work taking as its starting point the Brazilian policies for traineeship. It is sure that the importance of traineeship increases facing the profound changes in the work world and the constant scientific and technological development, causing the intensification of discussions on this issue and urging the academy to rethink its formation process, especially Social Work. The traineeship aims at linking formal education to the work world and to social practice. In Social Work, the supervised traineeship is part of the training process, and in this locus, the trainee is able to understand the institutional relationships and to develop new knowledge from knowledge of the social issues expressions that constitute the object of professional intervention. In this sense, the traineeship practice has as its main function contribute to help the trainee get hold of the social meaning of Social Work and build their professional, individual and collective identity. The challenge, nowadays, is to direct the trainee to the reflective and analytical training, so that the practices of Social Work will not focus only on immediacy.
\end{abstract}

KEYWORDS: Traineeship Policies, Supervised Training, Social Work, Vocational Training

\title{
REFERÊNCIAS BIBLIOGRÁFICAS
}

ANDRADE, M.A.R.A. Pensar e repensar a formação profissional: a experiência do curso de Serviço Social da Faculdade de História, Direito e Serviço Social - UNESP Franca. 2007. 197f. Tese (Livre-docência) - Faculdade de História, Direito e Serviço Social, Universidade Estadual Paulista “Júlio de Mesquita Filho”, Franca, 2007. 
BASSO, Guilherme Mastrichi. Notificação Recomendatória 741/2002. Disponível em: $<$ http://www.prg.unicamp.br/IIIENE/notificacao7412002.pdf>. Acesso em: 4 ago. 2008. BRASIL. Decreto 2.080, de 26 de novembro de 1996. Disponível em: $<$ http:/www.fclar.unesp.br/sta/indice\%20estagios\%20decreto\%202080\%2096.pdf>. Acesso em: 31 jul. 2008.

Decreto 87.497, de 18 de agosto de 1982. Disponível em: $<$ https://www.planalto.gov.br/ccivil_03/decreto/d87497.htm>. Acesso em: 31 jul. 2008. BRASIL. Lei 11.788, de 25 de setembro de 2008. Disponível em: $<$ http://www.planalto.gov.br/ccivil_03/_Ato2007-2010/2008/Lei/L11788.htm>. Acesso em: 15 jan. 2009

. Lei 6.494, de 7 de dezembro de 1977. Disponível em:

$<$ http://www.planalto.gov.br/ccivil_03/leis/16494.htm>. Acesso em: 31 jul. 2008. . Lei 8.859, de 23 de março de 1994. Disponível em:

$<$ http://www3.dataprev.gov.br/SISLEX/paginas/42/1994/8859.htm>. Acesso em: 31 jul. 2008.

BURIOLLA, M.A.F. O estágio supervisionado. São Paulo: Cortez, 1995

.Supervisão em Serviço Social: o supervisor, sua relação e seus papéis. São Paulo: Cortez, 1996.

COMISSÃO NACIONAL DE ESTÁGIO DO FORGRAD. Gestão administrativa e pedagógica do estágio. In: ENCONTRO NACIONAL DE ESTÁGIOS, 3., 2004, Campinas. Anais eletrônicos... Campinas: Unicamp, 2004. Disponível em: $<$ http://www.prg.unicamp .br/IIIENE>. Acesso em: 4 ago. 2008.

IAMAMOTO, M.V. O Serviço Social na contemporaneidade: trabalho e formação profissional. São Paulo: Cortez, 2007.

MARTINELLI, M.L. Serviço Social: identidade e alienação. São Paulo: Cortez, 2007. OLIVA, M.H.B.O estágio na formação profissional. Serviço Social \& Sociedade, São Paulo, ano 10, n. 29, p. 149-60, abr. 1989.

OLIVEIRA, C.A.H. S. O estágio supervisionado na formação profissional do assistente social: desvendando significados. Serviço Social \& Sociedade. São Paulo, ano 25, n. 80, p. 59-81, nov. 2004.

A centralidade do estágio supervisionado na formação profissional em

Serviço Social. 178 f. Tese (Doutorado em Serviço Social) Faculdade de História, Revista Serviço Social \& Saúde. UNICAMP Campinas, v. IX, n. 9, Jul. 2010 
Direito e Serviço Social, Universidade Estadual Paulista "Júlio de Mesquita Filho", Franca, 2003.

PACCHIONI, M.M. Estágio e supervisão: uma reflexão sobre a aprendizagem significativa. Lorena/SP: Stiliano, 2000.

PINTO, R.M.F. Estágio e supervisão: um desafio teórico-prático do Serviço Social. São Paulo: Pontifícia Universidade Católica, 1997.

. Política Educacional e Serviço Social. São Paulo: Cortez, 1986.

PROAC - Pró-Reitoria de Assuntos Acadêmicos - Coordenadoria Geral de Estágios.

Políticas de Estágios. [2008]. Disponível em: <http://estagio.proac.uff.br>. Acesso em: 11 ago. 2008.

SILVA, M.D. O estágio na formação profissional: elementos para análise. Serviço Social \& Sociedade, São Paulo, ano 15, n. 45, p. 147-255, ago. 1994.

SILVA e SILVA, M.O. A formação profissional do assistente social: inserção na realidade social e na dinâmica da profissão. São Paulo: Cortez, 1995.

SIQUEIRA, M.M.N.T. A formação do assistente social: a afetividade na supervisão de estágio. 2006. 196f. Dissertação (Mestrado em Educação). Pontifícia Universidade Católica, Campinas, 2006. 
